\title{
CONSTRUCCIÓN DEL SUJETO DE DERECHO AFRODESCENDIENTE EN MÉXICO. REFLEXIONES DESDE EL PACÍFICO SUR MEXICANO
}

\author{
CONSTRUCTION OF THE AFRO-DESCENDANT SUBJECT OF LAW IN MEXICO. \\ REFLEXIONS FROM THE MEXICAN SOUTH PACIFIC
}

\author{
Gloria Lara Millán*
}

\begin{abstract}
En el inicio del tercer milenio se cristalizaron instrumentos y definiciones jurídicas internacionales que impulsaron la formulación de estrategias de reconocimiento y atención a las poblaciones afrodescendientes en el mundo. En el caso mexicano, el reconocimiento de estas poblaciones atraviesa grandes desafíos, entre los que se halla el reconocimiento de su presencia viva y legítima por el derecho a la diferencia, la construcción de marcos de referencia que sustenten al sujeto de derecho, y la definición de acciones contundentes que atiendan de manera específica las demandas de los colectivos. Existen algunos avances en relación con los desafíos antes señalados, mismos que han sido fruto de esfuerzos realizados por los colectivos afrodescendientes organizados, la academia e instituciones gubernamentales y no gubernamentales. En esta comunicación me centraré en reflexionar acerca de los algunos desafíos en la construcción del sujeto de derecho afrodescendiente en México, haré referencia a la Consulta para la identificación de poblaciones afrodescendientes realizada entre el 2011 y 2012 por el gobierno mexicano y algunas acciones posteriores emprendidas por los colectivos demandantes en la ruta hacia el reconocimiento y lucha por sus Derechos Colectivos.
\end{abstract}

Palabras claves: Afrodescendientes, reconocimiento étnico, sujetos de derecho, derechos humanos.

In the beginning of the third millennium, instruments and international juridical definitions have been crystalized to promote the formulation of strategies for recognition and emphasis on African descents populations in the world. In the Mexican case, the African descents recognition is facing great challenges, including among them the recognition of their living presence and the legitimate right to be different, the construction of reference frameworks that sustain the subject of law, the definition of strong actions which specifically met what the communities are claiming. There are some progress concerning the challenges above-mentioned, same as they have been the results of efforts which the afro-descents organized communities, the academy and governmental and nongovernmental institutions have made. This communication will focus on reflections about some challenges in the construction of the afro-descendant subject of law in Mexico. I will refer to the Consultation for Identification of Afro-descendant people, made between 2011 and 2012 by the Mexican government and other subsequent actions undertaken by the claiming communities on the road to the recognition and fighting for their collective rights.

Key words: Afro-descendant, recognition of ethnic diversity, subjects of law, human rights.

\section{Introducción}

El texto que se presenta está estructurado en tres partes. En la primera parte se describe una breve introducción que sitúa históricamente a las poblaciones afrodescendientes en México. Posteriormente se presentan dos apartados en los que se trata de reflexionar acerca de algunos desafíos en torno a la construcción del sujeto de derecho afrodescendiente en México. En el primer apartado sitúo el contexto nacional e internacional en el que se afianza el reconocimiento de estas poblaciones en México. En el segundo apartado discuto acerca de la tarea que lleva a cabo el gobierno mexicano para identificar y definir del sujeto de derecho afrodescendiente; tarea que da respuesta a la demanda de colectivos que exigen se les reconozca como grupo étnico en la Constitución Política y da cumplimiento a los acuerdos internacionales concernientes a la eliminación de la discriminación racial y garantía de los derechos de las poblaciones afrodescendientes. El objetivo del texto es reflexionar respecto de las bases en que se sienta la construcción del sujeto afrodescendiente y proponer algunas líneas de análisis basado en los resultados de las Consulta para la Identificación de poblaciones afrodescendientes realizada en 2012 por el gobierno mexicano.

Las reflexiones centran atención en los colectivos afrodescendientes que se ubican en los estados de Guerrero y Oaxaca que abanderan la lucha por

* Universidad Michoacana de San Nicolás de Hidalgo, México. Correo electrónico:laram.gloria@gmail.com 
el reconocimiento. En estos dos estados de la república mexicana, la población afrodescendiente tiene reconocimiento en sus constituciones locales, bajo la categoría étnica de afromexicanos ${ }^{1}$. Por lo anterior, me centraré con mayor énfasis en la Costa Chica, región cultural compartida por las entidades citadas y lugar en donde se ubica la mayor parte de los colectivos organizados. Profundizaré en datos etnográficos obtenidos en el estado de Oaxaca, espacio donde he realizado con mayor profundidad el trabajo de campo y documental.

Para familiarizar al lector con el tema, las poblaciones afrodescendientes en México que describo en este texto hacen referencia histórica a las personas de origen africano que de manera forzada se introdujeron en calidad de esclavos a lo largo del período colonial y de migraciones provenientes del Sur de Estados Unidos y el Caribe en los siglos XIX y principios del siglo XX. Su inserción en la sociedad transitó por condiciones variadas, siendo esclavos y posteriormente semilibres y libres, así como en el desempeño del trabajo que realizaron en diversos lugares del territorio donde se asentaron. En el caso de la esclavitud forzada de hombres y mujeres durante más de tres siglos (Aguirre, 1994), el trabajo de numerosos esclavos intervino en el desarrollo y expansión de minas; obrajes; haciendas cañeras, agrícolas y ganaderas; así como en el servicio doméstico y las milicias. Cada contexto y período, determinó situaciones sociales y culturales específicas en la construcción de sociedades tanto en espacios rurales como urbanos.

Para el estudio de las poblaciones en cuestión existen particularidades a considerar:

- En la trata de esclavos en el período colonial se identifican dos períodos importantes: el primero y más intenso fue de 1521 a 1640, período en el que se calcula ingresaron alrededor de 268.000 personas. El segundo período, de 1640 a 1720 , las cifras son menos fiables en tanto que la procedencia de esclavos refiere a otros lugares en el Caribe (Serna, 2004). La esclavitud empezó a decaer como fuerza económica importante en la Nueva España alrededor de 1750 (Proctor, 2003) ${ }^{2}$. La trata de esclavos cierra de manera temprana a diferencia de otros países como Estados Unidos, Cuba y Brasil en 1865, 1885 y 1888, respectivamente (Hoffmann, 2007a). Con posterioridad, a lo largo de los siglos XIX y $\mathrm{XX}$ siguieron llegando varios miles de personas (sin registro de cifras) de Estados Unidos y el Caribe (Vinson III y Vanughn, 2004).

- Desde el siglo XVI, las poblaciones de origen africano denominadas como negros se mezclaron con indios, y en algunos casos con españoles. Es para el siglo XVIII que el mestizaje se intensificó entre indígenas y negros y aparecen otras denominaciones, a manera de "clasificaciones de hibridez" (Bernard, 1999), cuyas expresiones gráficas se observan en los cuadros de castas ${ }^{3}$ (véase Imagen 1). ${ }^{4}$

- En el período independiente, la abolición de la esclavitud se declaró por Hidalgo y José María Morelos en 1810; sin embargo este fue un proceso paulatino y diferencial en un territorio tan vasto como el de México. En las constituciones locales (de los estados) la abolición de la esclavitud tiene contenidos distintos y se valida en diferentes fechas. Por ejemplo para los estados de Oaxaca y Veracruz aparece la abolición en las constituciones locales en 1825 , y es hasta 1829 que Vicente Guerrero firmó el último decreto abolicionista (Olveda, 2013) . $^{5}$.

- El mestizaje como componente ideológico de la construcción de la nación en los siglos XIX y XX incluyó el pasado indígena en la conformación nacional, no así el de la población de origen africano. La dimensión histórica y cultural omnipresente del mestizaje es clave para comprender las prácticas racistas en México (Knight, 1990), estas coexisten con discursos y políticas gubernamentales nacionalistas que esconden tras de sí lógicas de prejuicio y discriminación (Moreno, 2008).

- En la lógica de perfeccionar al ciudadano mexicano deseable en la primera mitad del siglo XX (1920-1960), el Estado mexicano operó acciones de "ingeniería social" en materia de salubridad, la educación y la prevención social. Dichas acciones centraron sus esfuerzos en promover el mestizaje a manera de "unidad racial" y eliminación de las degeneraciones, para ello fue necesario el cambio de mentalidades y conciencia de los ciudadanos (Urías, 2007) ${ }^{6}$.

En la construcción nacional, las poblaciones afrodescendientes estuvieron excluidas del universo español e indígena y su inserción en la nación mexicana es desde los márgenes, en este sentido su impugnación por un lugar dentro de la sociedad 


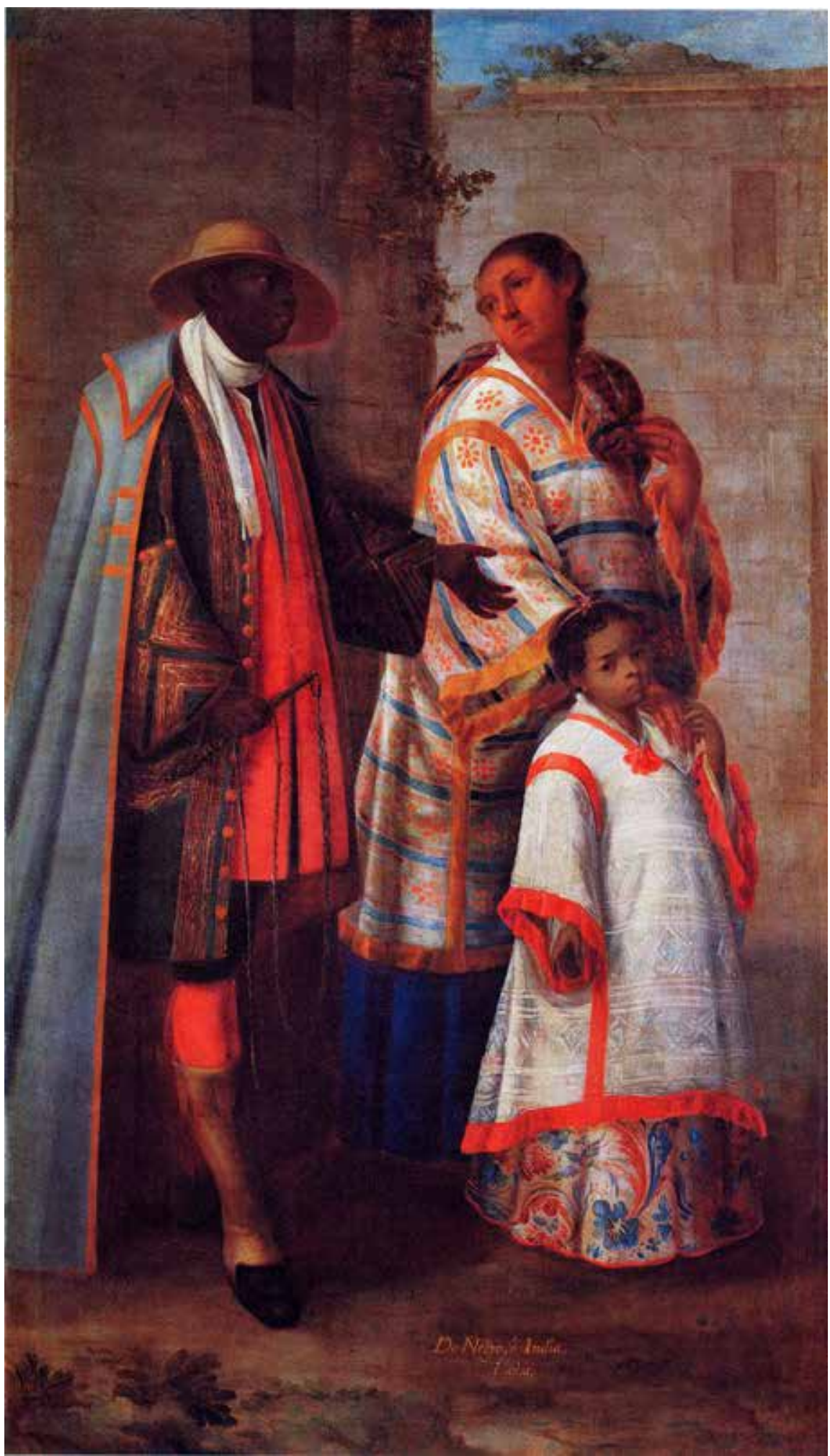

Imagen 1. Cuadro de castas. De negro e india, lobo, c. 1725.

Fuente: Katzew, Ilona (2004). Figura 91. Atribuido a José Ibarra, De negro e india, lobo, c. 1725, óleo sobre lienzo, 164 x 91 cm. Colección particular, España. 
trató de ajustarse a los límites normativos en cada espacio social en el que se hallaban.

Las consideraciones históricas antes citadas y numerosos estudios ${ }^{7}$, que no abordaremos aquí por no ser objeto principal de la reflexión, nos dan luz de las situaciones y contextos diversos en los que se insertaron las poblaciones afrodescendientes en México. Estas investigaciones marcan rutas o algunas pautas para entender a las poblaciones afrodescendientes contemporáneas, algunas de estas hoy se reivindican como negras, afromexicanas, afroindígenas, morenas y trigueñas, por citar varias de las formas en que se autoidentifican, según el espacio y la situación. A las notas arriba citadas, agrego tres puntos de reflexión que considero relevantes en la comprensión de las poblaciones en cuestión, mismos que no son novedosos, pero sí elementales.

El primero tiene que ver con la importancia de entender a las poblaciones afrodescendientes en interrelación con las poblaciones indígenas y mestizas con la que han construido el espacio donde habitan. Pensarlas como grupos separados simplifica su complejidad cultural. El segundo se relaciona con la indagación de las formulaciones históricas de alteridad (Briones, 2005), en las que se enmarcan especificidades a las que se asocian a ciertos grupos a manera de marcaciones selectivas racializadas o etnicizadas ${ }^{8}$. Esta cuestión toma relevancia para entender las particularidades locales, por ejemplo la forma en que se ha construido "lo negro", "lo racial" y su jerarquización en los contextos locales, así como los discursos de la etnicidad que se elaboran desde las instituciones, los actores y movimientos sociales localmente. La tercera se relaciona con el mestizaje; si bien este componente operó como una construcción ideológica, base de la identidad nacional, pensar en el mestizo como una categoría homogénea no ayuda a la reflexión, porque al interior hay jerarquizaciones de lo mestizo, cuyos marcadores distintivos (color de la piel, tipo de cabello, formas del cuerpo, lenguaje, entre otros) operan según el contexto y situación de encuentro?. Por ejemplo Peter Wade (2003) observa en Colombia la existencia de espacios particulares para lo indígena y lo negro en el mestizaje, sin embargo estos espacios están sujetos a las jerarquías de poder y el valor de las ideologías del blanqueamiento, mismas que favorecen lo blanco y menosprecian lo indígena y lo negro, o que restringen severamente el espacio que ocupan, limitando sus derechos. En este mismo tenor, las jerarquías entre las razas subyacen de las ideologías nacionalistas del mestizaje, de ahí que las raíces africanas en México en la década de 1980 se denominaran "la Tercera Raíz". Estas consideraciones más adelante me servirán en el desarrollo de mi argumentación.

\section{El espacio y su gente}

La población afrodescendiente en México habita en espacios diversos del país, tanto en espacios rurales y urbanos. Desde el período colonial, la población de origen africano se dispersó a distintos lugares de trabajo forzado y los procesos de misceginación variaron de un espacio a otro. La presencia de negros $\mathrm{y}$ afrodescendientes como actores participantes en el desarrollo de espacios regionales y urbanos se ha evidenciado en numerosas investigaciones de historia, antropología y otras áreas de conocimiento. Las expresiones culturales regionales han logrado visibilidad en numerosos foros culturales, académicos e institucionales donde se trata de enfatizar la particularidad de las raíces africanas mediante las tradiciones musicales y dancísticas. Sin embrago, la ausencia de los afrodescendientes en la historia oficial y su formulación como alteridad ajena a la construcción nacional, nos muestra fragmentos marginales de una historia olvidada que es vuelta a recordar. La diferencia está marcada por el tamiz del color, a la vez que de un mestizaje jerarquizado que trata de equipararse en los modelos de etnicidad indígena.

Actualmente es problemático trazar un mapa nacional de la presencia afrodescendiente en México, más bien afirmaría que está en construcción. Los trazos para definir al sujeto en cuestión se esbozan por medio de distintas miradas y actores: desde los colectivos negros o afromexicanos; desde individuos o grupos académicos; desde instituciones del Estado nacional y local y desde organismos internacionales. Si solo se considera a los colectivos que están activos políticamente, aquellos que se presentan en los foros, seminarios, reuniones y negociaciones con diferentes instituciones del Estado, y que de manera explícita se han unido a la demanda del reconocimiento étnico constitucional y políticas diferenciales para mejorar sus condiciones de vida, la protección y fortalecimiento a su patrimonio cultural y lingüístico (el caso de los mascogos), así como de combate a la discriminación y racismo. En esta lógica, los trazos de este mapa señalan movilizaciones de los siguientes colectivos localizados ${ }^{10}$ (véase mapa 1): 


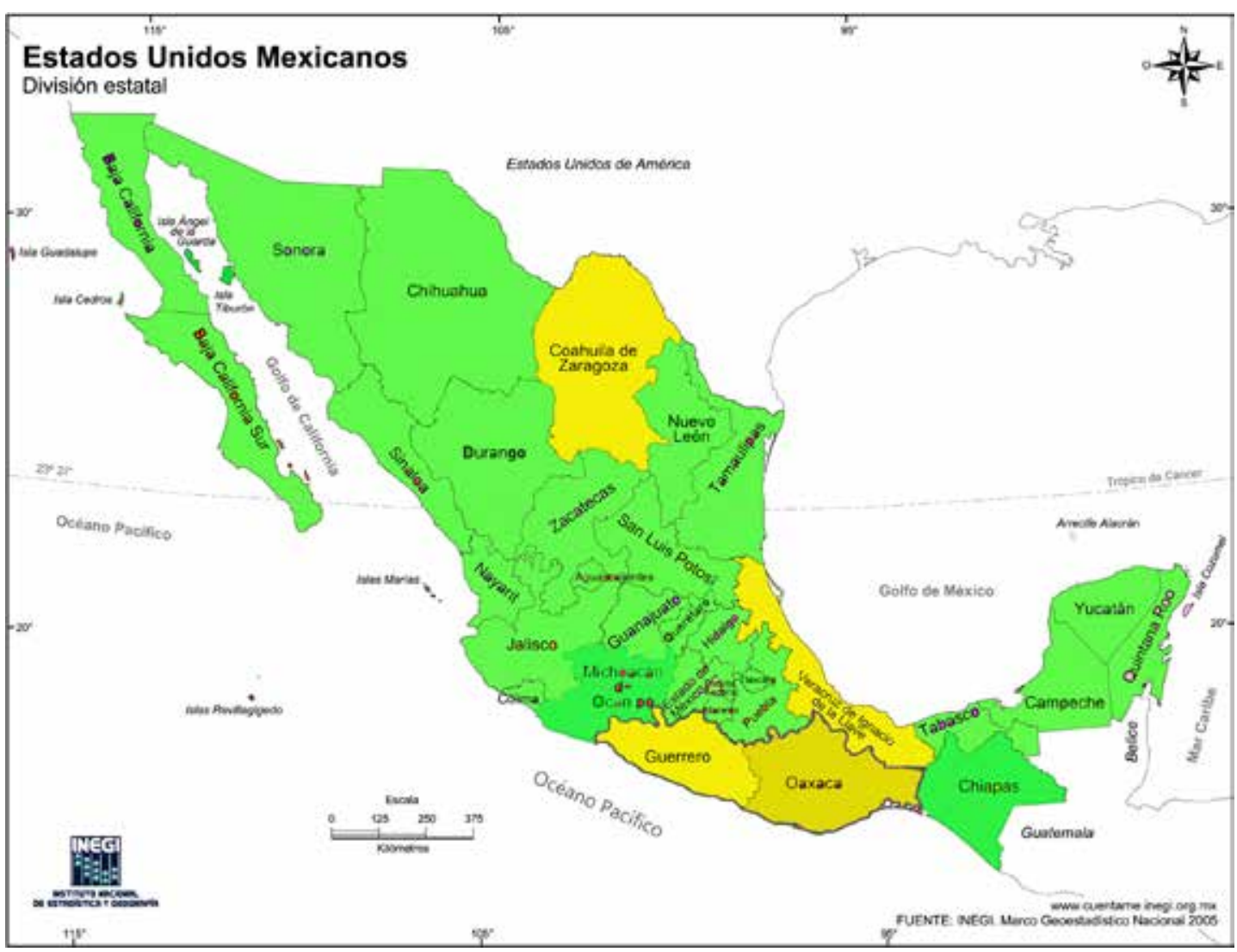

Mapa 1. Lugares en México asociados a lo afro. Fuente: INEGI, 2005, modificado por la autora para los fines de la investigación, 2017.

a) El caso de los mascogos en el estado de Coahuila, quienes demandan "reconocimiento y valor de su cultura, así como la intervención del gobierno mexicano para la expedición de visas especiales que posibiliten mantener continuidad cultural con las comunidades que forman parte de su pueblo" (CDI, 2012:52). A estas demandas se suma la importancia de proteger la lengua que hablan los mascogos denominada afroseminol ${ }^{11}$.

b) Comunidades en el estado de Veraruz en las que se reconoce la presencia africana y afrodescendiente. En estas comunidades no se han desarrollado procesos organizativos de reivindicación negra o étnica; sin embargo, las expresiones culturales "jarochas" forman parte de los repertorios culturales regionales que se asumen como mestizos, y sin reivindicar lo afro se reconoce la presencia de afrodescendientes ${ }^{12}$.

c) Las organizaciones y grupos comunitarios en la Costa Chica de Oaxaca y Guerrero. Los colectivos de los lugares citados han sido precursores en la demanda de reivindicación étnica y su reconocimiento constitucional. Las acciones en las que participaron estos grupos, primero en torno al rescate cultural afromestizo que iniciaron en la década de 1980. A lo largo de la década de 1990, después de varios encuentros de pueblos negros y de participación de otros actores externos se fueron madurando propuestas en torno al reconocimiento como grupo étnico. Sin embargo, es hasta después del 2001 que se dilucida un entorno más favorable, por una parte a partir de este año se establecen una nueva generación de derechos (en particular asociados a las comunidades y pueblos indígenas $)^{13}$ y relacionados con la firma de convenios internacionales ratificados por el gobierno mexicano. La Conferencia de Durban en el 2001 es uno de los referentes más importantes para el inicio de acciones institucionales a favor de la erradicación de la discriminación y racismo. 
A la par de la organización afromexicana en la costa Pacífica creció el interés en la academia mexicana y extranjera por los estudios afrodescendientes, ya no solo de corte histórico, sino contemporáneo, relacionado con luchas por la reivindicación afro. Desde principios de este siglo se han sumado algunos académicos como interlocutores y gestores con instituciones gubernamentales tanto a nivel local (estatal) como federal. Entonces, los foros académicos y culturales en torno a los afrodescendientes se multiplicaron y los líderes negros se articularon a diferentes redes del movimiento negro en América Latina. Un factor en la formación de redes sin duda es la comunicación por medio de internet, la que motivó a los líderes y organizaciones a formar parte de la comunidad negra, establecer sentimientos de pertenencia y solidaridad en torno a intereses específicos e información. Algunos líderes más que otros interactúan en el ciberespacio y la interacción en estas redes generó visibilización fuera del país, así como múltiples contactos con organizaciones nacionales e internacionales. En la última década, varios líderes negros latinoamericanos, representantes de embajadas y políticos locales han visitado la Costa Chica dando mayor visibilidad a los eventos organizados.

En este trabajo no profundizaré acerca del porqué la reivindicación negra afromexicana se expresa de manera incipiente en la década de 1990 y con mayor fuerza en la primera década del siglo $\mathrm{XXI}$; sin embargo es importante anotar que las reivindicaciones se inscriben en un momento en el que las políticas multiculturales se incorporan a los Estados como parte de los principios básicos que condicionan la legitimidad de los mismos. En este tenor, como lo menciona Paz (2004:363365), "la reivindicación de la diferencia ha sido un elemento madurado como parte de la crisis de los estados populistas; empero, el Estado mexicano no solo encontró la forma de abordar la política de la diferencia, sino también los límites en que se debe realizar, y con ello entrar en la retórica de las democracias del siglo XXI"14. Las poblaciones afrodescendientes no escapan de estos procesos y encuentran interlocutores para llevar sus demandas, ya no solo como campesinos y pobres, sino como un grupo con derecho a reivindicar su cultura y políticas de acceso a recursos públicos. Aquí retomo el primer punto de reflexión de la primera parte, no es posible enteder las reivindicaciones negras sin el movimiento indígena y esta cuestión cobra relevancia crucial en los espacios locales estatales.

La mayor parte de las poblaciones afrodescendientes actualmente se identifican por rasgos físicos, cuya apariencia se denota en el tono de la piel, la forma del cabello y en expresiones culturales como la danza, la música y las fiestas, entre otras. Aunque estos rasgos físicos no son homogéneos, en tanto se forman parejas entre indígenas, afromexicanos y mestizos, mismos que comparten espacios de vida. En las urbes, las y los afromexicanos parecen menos visibles. Rinaudo (2012) nos menciona para el caso de la Ciudad de Veracruz, que la dimensión étnico-racial no está necesariamente presente, y son otras distinciones las que se ponen en juego, como la clase o las diferencias regionales, y cuando llegan a operar categorizaciones étnicas son situacionales $\mathrm{y}$ tienen diferentes significados dependiendo del contexto ${ }^{15}$.

En México, como lo menciona Hoocker (20012:49) para las poblaciones afrodescendientes latinoamericanas, "tanto en el entorno urbano como rural, las poblaciones afrodescendientes no son suficientemente distintas de las culturas nacionales". No obstante, la dimensión somática se percibe y se asocia con características culturales particulares, las que participan en la conservación y significación de la frontera (Rinaudo, 2012:188). Lo anterior nos hace reflexionar acerca de las pervivencias decimonónicas, me refiero a las castas en tanto producto del mestizaje y cuyos orígenes étnicos están diluidos y en el que las raíces étnicas se evidencian por color de la piel (Fotografía 1).

Otro dato que concuerda con la presencia de los colectivos y comunidades demandantes del reconocimiento étnico son las cifras que se muestran en la Encuesta Intercensal realizada en 2015, cuyos datos (no obstante los sesgos que se muestran en el resultado) revelan que la población afrodescendiente se concentra particularmente en los estados de Guerrero, Oaxaca y Veracruz $(14.7 \%)$, entre otras entidades ${ }^{16}$. Un dato más para agregar es que los colectivos afromexicanos más activos y que constantemente están en las negociaciones y gestiones a favor del reconocimiento y generación de políticas públicas específicas pertenecen a los estados más pobres del país: en el año 2010 el estado de Guerrero ocupaba el $1^{\text {er }}$ lugar en rezago social y Oaxaca el segundo lugar (CONEVAL, 2015) ${ }^{17}$. Los registros de pobreza para las dos entidades citadas muestran que al 


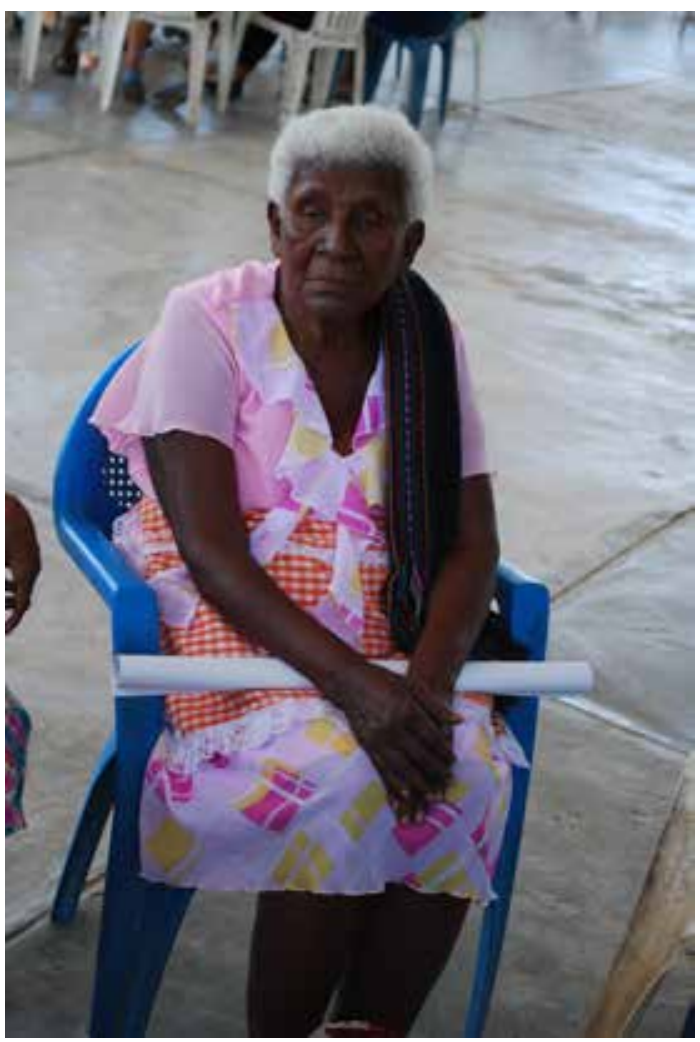

Fotografía 1.

Fuente: Mujer afromexicana, Santo Domingo Armenta, Oaxaca. Archivo fotográfico G. Lara, noviembre de 2011.

menos el $67 \%$ de la población vive en situación de pobreza (CONEVAL, 2010-2014).

Los colectivos que actualmente participan en la traza del mapa afrodescendiente participaron en la Consulta para la Identificación de las poblaciones afrodescendientes en México, realizada en el 2011, misma que se realizó en el contexto del Año Internacional Afrodescendiente. Como lo mencionan Velásquez e Iturralde (2016:233), a raíz de la declaratoria de 2011, la agenda acerca de este tema en México adquirió visibilidad política y se empezó a recibir atención por parte de instituciones públicas relacionadas con los derechos humanos y la prevención y eliminación de la discriminación.

\section{La reivindicación afromexicana en el Contexto político internacional}

El año internacional afrodescendiente declarado por la Organización de las Naciones Unidas en 2011 fue una plataforma de arranque, en particular para el caso de México, para las movilizaciones afrodescendientes en lucha por su reconocimiento. En este año el gobierno mexicano emprendió varias acciones para dar cumplimiento a los compromisos establecidos como parte del Programa de Acción Durban y de otros pactos asociados al combate a la discriminación. Considerando que la igualdad y no discriminación son principios aceptados y reconocidos por la comunidad internacional y no se admite acuerdo contrario ${ }^{18}$.

En este mismo año, el Comité para la eliminación de la discriminación racial de las Naciones Unidas (CERD) dictó recomendaciones generales para todos los Estados relativas a la discriminación racial contra la población afrodescendiente y consecuentes a la Declaración y Programa de Acción de Durban. Las acciones en las que los Estados adquieron compromiso de atención versaban diversos temas: dimensiones de la discriminación relacionadas con el género, discriminación racial contra los niños, protección contra la incitación al odio y la violencia racial, administración de justicia, derechos civiles y políticos; acceso a la ciudadanía; derechos económicos, sociales y culturales, y medidas en el campo de la educación ${ }^{19}$. Centraré algunas de las disposiciones al respecto: adopción de medidas legislativas para modificar la legislación y eliminar todas las formas de discriminación racial; en torno a las políticas públicas, aplicación de programas y estrategias que mejoren las condiciones de vida y su protección contra toda discriminación; aplicación de instrumentos que den cuenta de su distribución geográfica y las condiciones sociales y económicas con perspectiva de género; organización de campañas educativas y mediáticas para concienciar al público respecto de los afrodescendientes, su historia y su cultura, entre otras recomendaciones.

La institución que ha sido protagonista de las acciones del Estado mexicano para dar atención a las poblaciones afrodescendientes es el Consejo Nacional para Prevenir la Discriminación (CONAPRED) ${ }^{20}$. A lo largo de varios años, la institución ha invertido en generar información y estudios de las poblaciones afrodescendientes a nivel local y regional; cuenta también con publicaciones de difusión e investigación que han contribuido a ampliar el conocimiento de las poblaciones en cuestión. Los representantes de este organismo tienen un papel importante en los informes presentados ante el CERD y de organismos internacionales como la Comisión Económica para América Latina y el Caribe (CEPAL). 
La centralidad en el tema de la discriminación coloca a la institución no solo como interlocutora de las demandas de los colectivos en cuestión, sino como coordinadora de acciones en conjunto con otras instituciones del Estado. Las acciones que han tenido mayor resonancia en los discursos de la propia institución son la realización del Foro Nacional de Poblaciones Afrodescendientes en México en 2012; la inclusión por primera vez de una pregunta respecto de población afrodescendiente en la Encuesta Intercensal del Instituto Nacional de Estadística y Geografía (INEGI) en 2015 (véase Imagen 2); así como la elaboración del Plan de Trabajo para instrumentar nacionalmente acciones en el marco del Decenio Internacional de los Afrodescendientes 2015-2024 21 .

En el contexto del 2011, las demandas de los colectivos afrodescendientes adquirieron mayor legitimidad y los líderes de los colectivos se posicionaron en mejores condiciones para negociar acciones tendientes al reconocimiento constitucional y políticas públicas específicas. Recordemos que estos colectivos, como se dijo en el apartado anterior, para este momento son más visibles y han establecido redes a nivel nacional e internacional, tanto en el ámbito académico como en el movimiento afrolatino. Este momento fue coyuntural para las organizaciones; quienes buscaron canales de interlocución institucionales para solucionar no solo las demandas a largo plazo, que es el caso del reconocimiento étnico, sino además las demandas inmediatas que requerían financiamiento para el desarrollo social y económico.

Una de las acciones propuestas desde el Estado en el 2011 fue realizar una primera consulta para identificar a la población afrodescendiente. Dicha labor institucional no fue realizada por CONAPRED, quien se encargó de la organización y operación fue la Comisión Nacional para el Desarrollo de los pueblos indígenas $(\mathrm{CDI})^{22}$. En este año, la CDI se encargó de preparar el terreno para incluir la representación afromexicana dentro de las sesiones del Consejo Consultivo de la CDI. En mayo de 2011 se incluyó por primera vez la representación del pueblo afromexicano (CDI, 2011).

La encomienda de esta labor a la CDI, que particularmente da atención a los pueblos indígenas, posiblemente se halló en que la estructura institucional tiene un marcado arraigo en el medio rural, cuenta con infraestructura en diferentes regiones del país, capacidad de movilización y en algunos casos reconocimiento por parte de las comunidades. En el caso de Oaxaca, el Centro Coordinador para el Desarrollo Indígena de Jamiltepec (CCDI) fue un referente del Estado desde mitad de siglo XX y protagonizó el desarrollo regional al menos durante dos décadas: 1950-1970 (Lara, 2012). Posteriormente, sus tareas se redujeron y hoy mantiene algunas líneas de acción para el desarrollo económico, social y cultural de los pueblos indígenas de la región.

Instituciones como la CCDI junto con Unidad Regional de Culturas Populares fueron las primeras instituciones gubernamentales que abrieron la posibilidad de brindar pequeños apoyos a las comunidades afromexicanas, principalmente para preservación y difusión de las expresiones culturales y producción literaria. En suma, la tarea fue encargada a la institución cuya trayectoria tiene reconocimiento social en la región y poder de convocatoria para reunir a los líderes de las organizaciones negras y afromexicanas de la región. Aquí subrayo que los líderazgos de las organizaciones convocadas
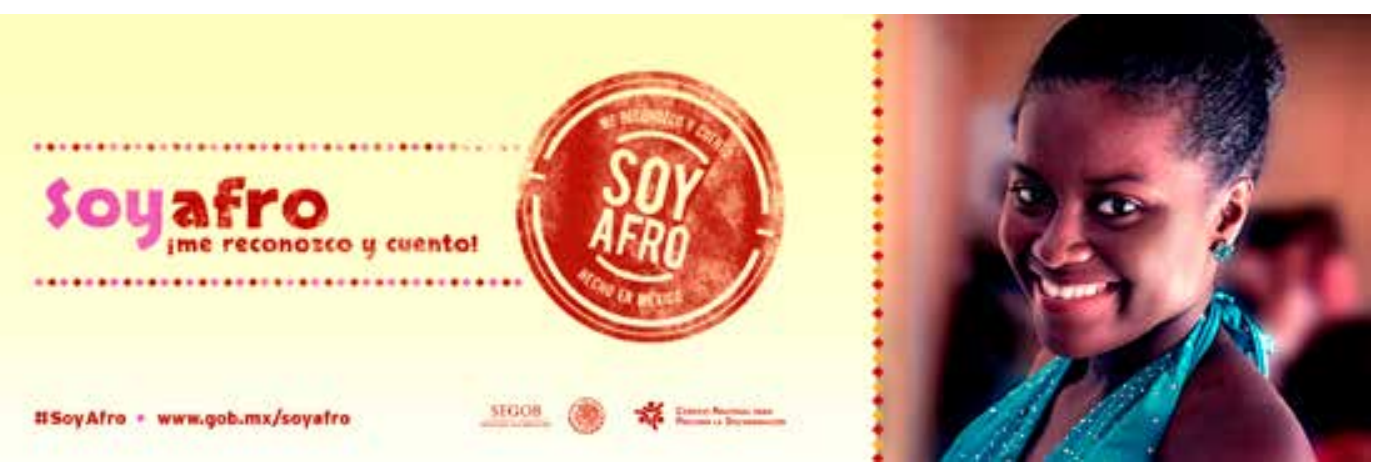

Imagen 2. Campaña "Soy Afro". Con el lema "Me reconozco y cuento".

Fuente: http://www.conapred.org.mx/index.php?contenido=registro_encontrado\&tipo=2\&id=5363 
en 2011 fundamentalemente eran hombres. En la actualidad el panorama del liderazgo afromexicano está en proceso de cambio y son varias mujeres líderes las que hoy se observan en los foros nacional e internacionales.

\section{La consulta afrodescendiente en el Pacífico sur mexicano}

La consulta afrodescendiente propuesta por el gobierno mexicano tuvo por objetivo reconocer mediante un proceso de consulta a las comunidades de los pueblos afrodescendientes de México y sus principales características (CDI, 2012). En el proceso participaron organizaciones afromexicanas, representantes gubernamentales y académicos. $\mathrm{La}$ participación y el aval de los actores mencionados dio legitimidad de la consulta.

Los estados en que la CDI definió realizar la consulta fueron: Coahuila, Guerrero, Michoacán, Oaxaca y Vercruz. La operación de las acciones se definieron en cinco etapas, pasando por establecimiento de acuerdos, el diseño de la consulta, la aplicación, la integración y evaluación de resultados, y la integración y entrega de resultados. Para este momento se habían integrado dos representantes afromexicanos al Consejo Consultivo de la CDI, una representante por el estado de Oaxaca y un representante por el estado de Guerrero, mismos que se sumaron a supervisar las actividades en sus propios estados y regiones.

La consulta fue realizada en comunidades de la región Costa, específicamente en dos demarcaciones distritales: Santiago Jamiltepec y Santa Catarina Juquila (véase mapa 2), espacios que tienen presencia de organizaciones negras y afromexicanas. La elección de las comunidades que fueron consultadas se consensaron con los líderes de las organizaciones y fueron discutidas al interior del Comité Técnico conformado por académicos, instituciones y organizaciones afromexicanas ${ }^{23}$ a fines de junio de 2011.

Los elementos que servirían para caracterizar a las comunidades derivaron del modelo étnico indígena avalado por consultores de la CDI (véase Cuadro 1). Considerando estos elementos, la CDI elaboró un instrumento en forma de cuestionario, el que fue discutido con las organizaciones afromexicanas

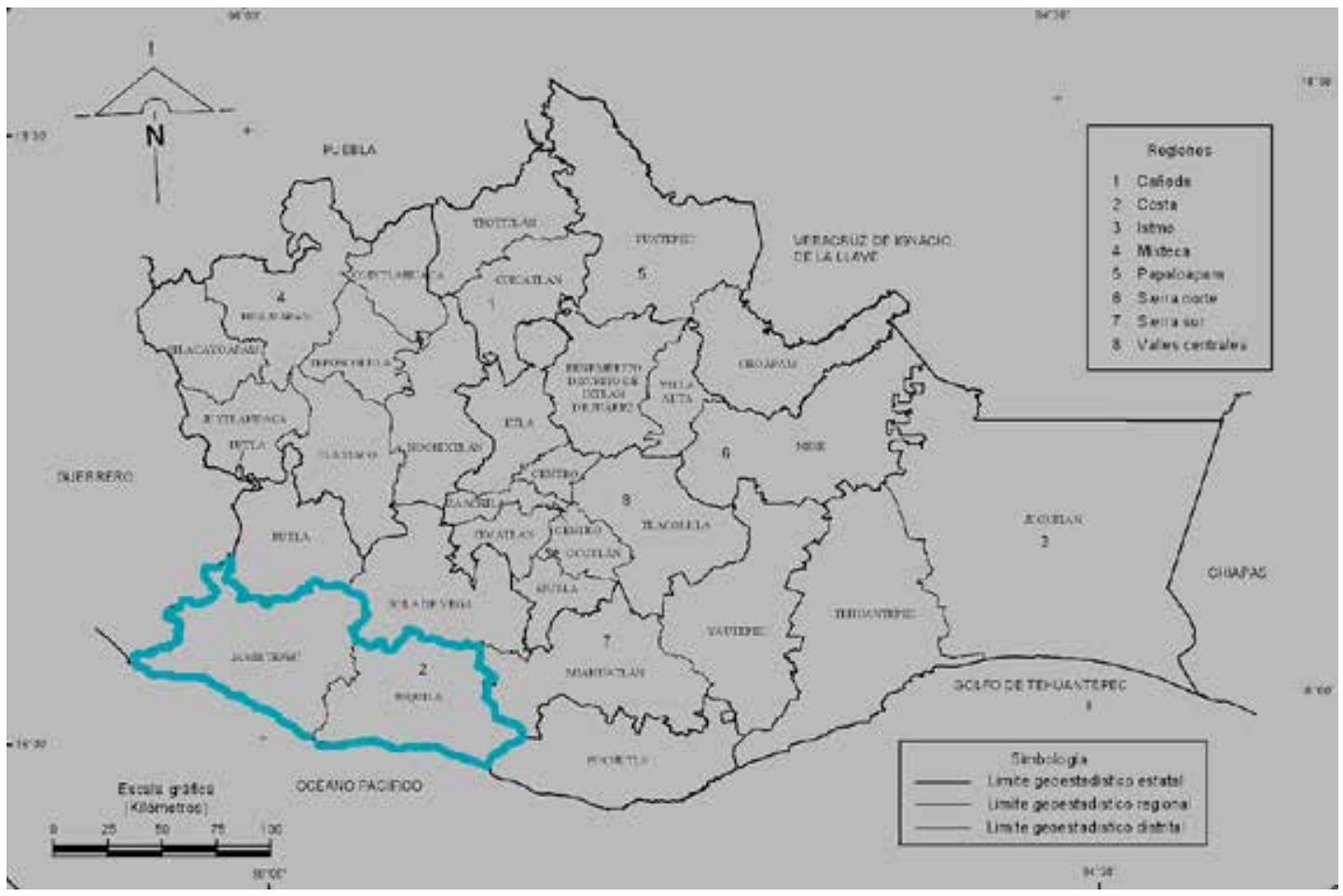

Mapa 2. Distritos de Santiago Jamiltepec y Santa Catarina Juquila en el estado de Oaxaca.

Fuente: División geoestadística municipal (Regiones y distritos), en Anuario Estadístico Oaxaca, Edición 2010. Instuto Nacional de Estadística y Geografía. 
Cuadro 1. Descripción de elementos definitorios para la caracterización de la organización colectiva ${ }^{24}$

\begin{tabular}{ll}
\hline \multicolumn{1}{c}{ Unidad } & \multicolumn{1}{c}{ Desarrollo } \\
\hline Social & $\begin{array}{l}\text { Demografía: refiere al entramado de personas, hogares y grupos de personas que establecen y mantienen } \\
\text { relaciones de diversos tipos, constituyendo una red de relaciones estable y reconocible, que puede ser } \\
\end{array}$ \\
& $\begin{array}{l}\text { diferenciada de otras (contiguas u ocasionales). Estas relaciones se expresan regularmente bajo formas } \\
\text { institucionalizadas como el parentesco (real y simbólico), los grupos de sexo y edad, organizaciones } \\
\text { funcionales, el vecindario, etc. La comunidad puede ser entonces comprendida como una unidad social. }\end{array}$
\end{tabular}

Económica

Cultural

Asentamiento en un territorio identificable

Reconocimiento de autoridades propias

Pertenencia social

Relaciones con actores externos
Economía: refiere a las formas de articulación de las unidades productivas familiares en diversos aspectos, como los arreglos relativos al aprovechamiento de los recursos (principalmente la tierra, el agua y los bosques), los arreglos técnicos y económicos relacionados con la gestión de la producción y los arreglos acerca de la prestación e intercambio de trabajo. La comunidad puede ser entonces comprendida como una unidad económica.

Identidad: refiere a las relaciones que se establecen en prácticas culturales comunes, como la memoria de la historia larga y la historia cercana, la ritualidad y las fiestas ligadas a la religiosidad y otras, que dotan al entramado social de un sentido de colectividad que la distingue de otras colectividades. La comunidad puede ser entonces comprendida como una unidad cultural.

Territorialidad: refiere a las relaciones implicadas en el amplio conjunto de asuntos que tienen lugar en el entorno físico en el que vive una colectividad, como la ocupación del espacio para varios fines (el asentamiento, por ejemplo), la obtención de bienes necesarios para asegurar su vida material, la materialización de la ritualidad, el ejercicio de la autoridad y en general el aseguramiento de su reproducción social y cultural. Esta visión de territorio supera la ficción jurídica de propiedad y le atribuye la cualidad de plataforma de oportunidades, espacio de expresión cultural y de organización comunitaria. De todas maneras sus expresiones más visibles son los regímenes de propiedad y de división político-administrativa. La comunidad puede ser entonces comprendida como una unidad asentada en un territorio.

Autoridad: refiere a la organización de las relaciones de poder y de prestigio y a la estructura que las organiza. El reconocimiento de autoridades propias implica además la aceptación de un cuerpo-difuso-de maneras de proceder en la regulación de estas relaciones y de resolución de los conflictos que pudieran ocurrir al interior de las mismas. La comunidad puede ser entonces comprendida como una unidad que reconoce autoridades propias de acuerdo con sus usos y costumbres.

Adscripción: refiere al conjunto de relaciones de carácter simbólico por las que una colectividad se comprende a sí misma como una unidad social, económica y cultural y se atribuye, a sí misma y a sus miembros, rasgos de distintividad. Uno de estos rasgos es la conciencia de su pertenencia a un pueblo determinado.

Articulación: refiere a las relaciones que se establecen entre la comunidad y otras entidades sociales y políticas del entorno, como otras comunidades, los municipios y sus agencias, las instituciones públicas federales y estatales, las empresas y las organizaciones civiles de promoción. Interesa el examen de estas relaciones en tanto dan cuenta de la asignación del estatuto de comunidad desde actores externos.

Fuente: CDI (2012:31).

y posteriormente aplicado en grupos focales en 14 comunidades que se establecieron como sedes microrregionales (véase Cuadro 2). La consulta no prentendió establecer una muestra representativa de las comunidades afrodescendientes, sino lograr que mujeres y hombres de la región participaran en este primer ejercicio para reunir información y ampliar el conocimiento de las poblaciones en cuestión. Participaron alrededor de 1.400 personas pertenecientes a 79 comunidades de la región.
La base jurídica en la que se sostuvo la consulta fue el artículo 2 de la Constitución de los Estados Unidos Mexicanos en la que se identifica que:

“...son comunidades integrantes de un pueblo indígena, aquellas que formen una unidad social, económica y cultural, asentadas en un territorio y que reconocen autoridades propias de acuerdo con sus usos y costumbres. $\{\ldots\}$ Sin perjuicio de los 
Cuadro 2. Sedes para la realización de la consulta.

\begin{tabular}{ll}
\hline \multicolumn{1}{c}{ Municipio } & \multicolumn{1}{c}{ Sede de evento } \\
\hline Santa María Cortijos & Santa María Cortijos \\
San José Estancia Grande & San José Estancia Grande \\
Santo Domingo Armenta & Santo Domingo Armenta \\
Santiago Tapextla & Santiago Tapextla \\
Santiago Llano Grande & Santiago Llano Grande \\
San Juan Bautista Lo De Soto & San Juan Bautista Lo De Soto \\
Mártires de Tacubaya & Mártires de Tacubaya \\
Pinotepa Nacional & Lagunillas Pinotepa \\
& Collantes \\
Villa de Tututepec de Melchor Ocampo & Corralero \\
& Santa Rosa De Lima \\
Santiago Jamiltepec & El Cacalote \\
Santa María Huazolotitlán & Charco Nduayoo \\
\hline
\end{tabular}

derechos aquí establecidos a favor de los indígenas, sus comunidades y pueblos, toda comunidad equiparable a aquellos tendrá en lo conducente los mismos derechos tal y como lo establezca la ley".

El artículo segundo extiende la protección de derechos indígenas a las comunidades equiparables. En esta disposición jurídica sería posible otorgar la categoría de "entidades de interés público" a las poblaciones afromexicanas, misma que otorgaría derechos y obligaciones como elementos básicos de la personalidad jurídica. En esta lógica, la legislación vigente protegería el goce de derechos colectivos a estas poblaciones. Sin embargo, hasta ahora no existen disposiciones claras que reglamenten el ejercicio de este derecho como comunidades equiparables. Como lo menciona el CONAPRED (2014:261), "la falta de claridad en la normativa ha provocado la invisibilización de estos pueblos, obstaculizando así el ejercicio de sus derechos".

El sustento legal bajo el que se estableció la base para conocer y reconocer al sujeto de derecho afrodescendiente resultó frágil e inconsistente. Por una parte, se hallan las lagunas jurídicas que no reglamentan el alcance de los derechos de las comunidades que deseen equipararse $\mathrm{y}$, por otra parte, el modelo étnico difícilmente tendrá correspondencia a la trayectoria histórica de las poblaciones afromexicanas en el país. Analicemos con mayor detenimiento.

Hay que anotar que varias definiciones en el texto constitucional son estrechas incluso para las mismas comunidades indígenas. Bárcenas (2004:219) nos muestra cómo los conceptos utilizados en el texto en cuestión petrifican los cambios sociales en las comunidades indígenas y cita dos ejemplos al respecto: 1) la definición de comunidad se reduce a la existencia de comunidades indígenas en un solo territorio, cuando en la realidad hay comunidades que se ubican en más espacios territoriales y forman una unidad social, como es el caso de los migrantes; 2) la exigencia del reconocimiento de autoridades propias de acuerdo con sus usos y costumbres, cuando en el texto solo puede dejarse como el reconocimiento de sus propias autoridades.

Si estos conceptos constriñen a las comunidades indígenas, el escenario jurídico para los afromexicanos es más complejo. Estudios recientes hechos por la CONAPRED (2014) muestran que no es viable la figura de "comunidades equiparables" para reconocer a las poblaciones afromexicanas. $\mathrm{La}$ vía factible desde la institución es hacer cambios constitucionales que puedan brindar un sostén real al reconocimiento de las y los afromexicanos en el país. La modificación integral al artículo $2^{\circ}$ constitucional debe incluir expresamente a la población afromexicana, así como el cambio a varios artículos vinculantes ${ }^{25}$. La propuesta del CONAPRED antes citada no cuestiona el modelo étnico, aunque reconoce diferencias entre las poblaciones indígenas y afromexicanas. Si bien lo étnico no es el foco de análisis de la publicación, es un punto relevante, en tanto lo juridíco no solo es la ley (Schuler, 1987 citada en Facio, 1992).

Facio (1992:65), estudiosa del derecho, insiste que el fenómeno jurídico tiene tres ámbitos principales: la ley como texto normativo (formal 
normativo); la estructura operativa (componente estructural) y la cultura ciudadana (componente cultural).

En el primer componente formal-normativo, para que las leyes existan y sean reconocidas como tales, tienen que estar escritas y formalmente promulgadas. En este punto, para que las poblaciones afrodescendientes puedan ser sujeto de derechos colectivos es necesario un sustento jurídico firme que hasta ahora no existe; como ya se mencionó, se requiere su reconocimiento de manera explícita o instrumentos jurídicos reglamentarios en los que se pueda sostener. En el segundo componente estructural, el que hace referencia a la estructura en la que opera la ley, a las instituciones y a las personas que están en la ejecución de la misma. Este es un punto con enorme trascendencia, en tanto que los operadores de las leyes dan significados e interpretan los alcances que tienen. $\mathrm{Al}$ respecto, las y los funcionarios de la CDI interpretaron que el artículo $2^{\circ}$ podía tener suficiente alcance jurídico para que las comunidades afromexicanas pudieran pensarse como comunidades equiparables. Sin embargo, esto no es posible jurídicamente por la ausencia de la reglamentación al respecto. Además, insistiría que el modelo étnico requiere de mayor reflexión y flexibilidad para responder a las condiciones históricas afrodescendientes.

El tercer componente es la cultura ciudadana, un aspecto tan importante como los anteriores, refiere a la construcción histórica de la ciudadanía, a la experiencia ciudadana en la socialización de la norma y su aplicación cotidiana. Este elemento sin duda jugó un papel importante y es parte fundamental de las reflexiones alrededor de la consulta. Detallo a continuación.

Es necesario señalar que existe una interrelación entre todos los componentes mencionados, de tal manera que podemos observar cómo un componente incide sobre otro. Por ejemplo, del componente cultural al componente normativo, Facio (1992:67) menciona:

"El componente político cultural determina el contenido del componente formal-normativo \{... \} quienes hacen las leyes son personas de carne y hueso que están impregnadas de actitudes, juicios y preconceptos con respecto a las personas a quienes va dirigidas, especialmente cuando esas personas pertenecen al sexo femenino, a una raza/etnia discriminada, a un grupo minoritario, etc.".

Por ejemplo, en México el español no es una lengua oficial. El artículo $2^{\circ}$ de la Constitución establece que el reconocimiento de los pueblos y las comunidades indígenas en todo el territorio nacional implica también el reconocimiento etnolingüístico y de asentamiento físico de los mismos, lo anterior, supone la obligatoriedad para "preservar y enriquecer sus lenguas, conocimientos y todos los elementos que constituyan su cultura e identidad" (Diario Oficial, 2012). Al respecto, existen programas que promueven un enfoque intercultural en el Sistema Educativo Nacional. Sin embargo, en la realidad cotidiana, la lengua en la que se imparte la educación escolarizada en la mayor parte del territorio nacional es el español, la interculturalidad como eje transversal en el ámbito educativo todavía es una tarea pendiente. Existen autoridades educativas que no dan importancia a este tema y esto se denota claramente en la ausencia de presupuesto para tal fin. Estudios realizados por el Instituto Nacional de Lenguas indígenas mencionan que:

"La discriminación hacia la población indígena, y sobre todo hacia los hablantes de lenguas indígenas durante generaciones, ha provocado que se oculte el uso de las lenguas indígenas, disminuyendo sus ámbitos de uso. La discriminación, la violación de los derechos humanos y lingüísticos por parte de los servidores públicos y el incumplimiento de las tareas institucionales han tenido gran responsabilidad en la pérdida de muchos idiomas mexicanos. La responsabilidad de todos los mexicanos ante estas injusticias es muy alta y debemos recuperar el tiempo perdido" (INALI, 2008:17).

Para el caso de la población afromexicana, estudios lingüísticos revelan que desde el siglo XVII hasta comienzos del siglo XX se registraban variedades híbridas afrohispánicas, entendidas también como lenguas criollas (Zimmermann, 1992 citado en Lipsky, 2007), habla bozal afromexicana (siglos XVII y XVIII) o interlengua afro-hispanoindígena (siglo XIX). David Chávez discute al respecto el origen del habla vernácula al analizarlo en una comunidad de la Costa Chica. El estudio 
detalla que las variantes costeñas y caribeñas tienen particularidades del español antiguo, no estandarizado, proveniente de marineros andaluces cuyo español no era el estandarizado. En el desarrollo de su investigación muestra que el español antiguo que se habla en la Costa Chica no tiene influencias idiomáticas africanas y que muchos de los términos empleados son de origen indígena (Chávez, 2014: 86-87,101). Esto es comprensible por la convivencia con población indígena desde el período colonial, además del contacto con múltiples personas en temporalidades en que los puertos y zonas de embarque de mercancía e intensa circulación de personas y productos hablaban el español. Chávez afirma que los cambios en rutas comerciales dejarón atrás estas variantes lingüísticas que desaparecieron en las metrópolis, derivando posteriormente en reductos marginales.

En el siglo XX se menciona que el habla afromexicana en algunas regiones del país "reflejan las huellas lingüísticas del aislamiento y el abandono sociocultural" (Lipsky: 2007:37), y además se muestran numerosas regiones en el que estas características fonéticas son identificables ${ }^{26}$. Lipsky menciona que existe desconocimiento del patrimonio lingüístico y cultural africano; además "ningún tratado de dialectología mexicana reconoce una presencia africana en la formación de las zonas dialectales" (Lipsky, 2007:43).

Lo que quiero poner en discusión al mencionar el habla vernácula popular en la Costa Chica, no es la defensa de un origen africano, en tanto que diversos estudios muestran que en varios espacios latinoamericanos la variación lingüística no se relaciona con influencias idiomáticas africanas (véase López 1998; Schwegler, 1998, citado por Chávez $2014)^{27}$ y para el caso mexicano el habla no es exclusiva de las poblaciones afromexicanas. Lo que quiero destacar es el lugar margen que tiene como variante lingüística en los estudios y reconocimiento histórico oficial, asociado al desconocimiento de la participación de las poblaciones de origen africano en el desarrollo de país.

Sumado a lo anterior, la región de la Costa Chica de Oaxaca y Guerrero eran espacios márgenes, carentes de instrucción escolar y servicios antes de la existencia de la carretera que une a los Puertos de Acapulco y Puerto Escondido (Lara, 2012). La lengua vernácula, identificada como español antiguo, es practicada de forma marginal y vista como un vestigio, en tanto que su sobrevivencia está marcada por la discriminación. Varios elementos han incidido en el giro del lenguaje en las poblaciones costeñas afromexicanas: la discriminación, la escolarización y la migración, entre otros.

En la consulta para la identificación afrodescendiente, refirieron acerca de esta forma "antigua de hablar". Estas formas solo se muestran en el entorno familiar y en algunos espacios comunitarios. El uso en otros lugares es motivo de burla y signo de poca preparación escolar y atraso. Un líder afrodescendiente de la comunidad de Pinotepa Nacional me decía que "todavía tres décadas antes, era notoria la gente física", es decir, aquellas personas que tenían la oportunidad de salir para ir a la escuela y hablaban un español en el que se pronunciaba la letra s para hablar, en un español más correcto. En estos tiempos, afirmaba el líder, era más difícil estudiar, las escuelas solo ofrecían algunos grados escolares y se ubicaban en lugares a veces inaccesibles para el común de las personas. El líder tuvo la oportunidad de estudiar en una ciudad y adquirió herramientas que le fueron útiles para conseguir un trabajo fuera del campo. Salir, estudiar, dejar el habla de los negros significaba progresar.

Hablar de manera antigua, decían en reunión las personas consultadas, "ya no se usa", "se procura que los hijos y los nietos progresen, que no se arriesguen a burlas". "En la escuela y en la casa se corrigen" (testimonio de mujeres, San Juan Bautista Lo de Soto, 2011). También se menciona que es notorio el cambio generacional en el uso de las palabras y medios para comunicarse: "los muchachos ya utilizan nuevas palabras, palabras modernas que ya no entendemos los viejos, ya cambiaron muchas cosas con las computadoras y los teléfonos que cargan" (mujer, Santo Domingo Armenta, 2011). Igual que en otros tiempos, fue la adquisición del español, ahora perfeccionar el idioma, hacia una pronunciación considerada correcta, les da acceso e inclusión en los espacios.

Este ejemplo nos da pie para situar la necesidad de que las instituciones pongan en contexto que el camino hacia el reconocimiento afrodescendiente requiere vincular la construcción de la norma con los aspectos operativos y de cultura ciudadana. $\mathrm{La}$ consulta realizada como parte de las acciones que el estado mexicano emprende sin duda muestra un esfuerzo por generar conocimientos, entender los contextos de reivindicación afromexicana, conocer a los protagonistas de la movilización etnopolítica y establecer contacto con las personas que a futuro 
serán las beneficiarias de políticas públicas específicas. Los resultados y aprendizajes en el ejercicio de la consulta pueden organizarse en varias líneas de investigación y de exploración. Me limitaré a mencionar algunas líneas que me parecen importantes en la construcción futura de la normativa que está pendiente para el reconocimiento constitucional.

Parto de la idea, a manera como lo plantea Facio (1992), que la ley es instrumento que incide profundamente en el componente político cultural. El cambio no es automático, es un largo proceso en el que se requiere de establecer normatividades que favorezcan mover estructuras concretas y establecidas para abrir brecha en el trabajo ciudadano, en el que se requiere transformar la forma de mirar la diferencia y la diversidad.

Primera línea. Las bases del reconocimiento tienen que ampliarse desde la base ciudadana. El derecho a conocer la ley, en este caso los derechos otorgados en la Constitución local como es el caso del estado de Oaxaca. Para el momento en que se realizó la consulta en 2011, la gran mayoría de las personas desconocía la ley para los pueblos y comunidades indígenas de Oaxaca publicada en 1998. Desconocía la celebración del 2011 como Año Internacional Afrodescendiente, el que no apareció en la agenda educativa gubernamental. El contacto con las personas participantes se sujetó a los contactos de las organizaciones afromexicanas y a su poder de convocatoria. Es decir, no se involucró a instituciones para ampliar el llamado en las comunidades donde se realizó la consulta. Los riesgos en este tipo de convocatoria es el sesgo de la información y la exclusión de otras voces.

En la consulta varias personas preguntaban por qué no estaban representantes de otras personas de otras comunidades donde había gente morena o negra y también surgió la duda del ¿por qué hasta ese momento se tenía interés por los negros? si anteriormente ninguna institución se había preocupado. Ciertamente, es reciente el proceso organizativo de los colectivos reivindicados como negros, así como la gestión de demandas específicas de estas comunidades. El Año Internacional Afrodescendiente es una coyuntura política, afortunada para visibilización, y que se enmarca en la "internacionalización de la retórica de la diversidad como derecho humano y valor" (Briones, 2005:11).

Segunda línea. La categoría de identidad étnica en México está definida por medio del indígena. Dicha categoría se ha trasformado a lo largo del tiempo, especialmente a fines del siglo $\mathrm{XX}^{28}$, las vertientes de estos cambios históricos son varias: el movimiento nacional indígena; "el pasaje de los indígenas de objetos a sujetos del derecho internacional" (Barch, 1994: citado en Briones 2005:10); marcos legales internacionales suscritos por el gobierno mexicano; el avance del neoliberalismo concertado con el proceso de transnacionalización ${ }^{29}$, entre otros ${ }^{30}$. Es decir, en las articulaciones entre sistemas económicos, estructuras sociales, instituciones jurídico-políticas y aparatos ideológicos prevalecientes en las formaciones nacionales de alteridad (Briones, 2004:17). La misma autora enfatiza que estas formaciones no solo producen categorías de identificación-clasificación, sino que administran jerarquías socioculturales. Particularmente en Oaxaca existe un discurso gubernamental retórico de la diversidad, en él, hay un esfuerzo consistente en mostrar la riqueza cultural. Esto se observa en numerosas representaciones sociales, una de ellas que ensalza la diversidad y lo indígena es la fiesta de la Guelaguetza. ${ }^{31}$

La población afrodescendiente, también nombrada "Tercera raíz" en México, que sin formar parte de los elementos míticos de la conformación de la nación y parte de la categoría étnica definida oficialmente y a la vez distinta al modelo imaginario de mestizo, actualmente pasa por la construcción étnica, cuyo modelo pone por adelantado el sentido de pertenencia. La justificación para ser sujeto de derecho, como vimos en páginas anteriores, se enmarca en el modelo étnico indígena producido en el país. La inclusión/exclusión en este modelo, ajustado hasta para algunas comunidades indígenas, muestra los elementos definitorios. Pretender cuestionar la ideología étnica (Hale, 2007) ${ }^{32}$ tiene una enorme complejidad política. Sin embargo, la categoría étnica de grupo étnico tendría que rediscutirse y "desindigenizarse", sin que esto signifique entender a las poblaciones afrodescendientes separadas de las indígenas y mestizas.

Tanto lo indígena como lo mestizo está presente en la construcción y diferenciación afromexicana. Tomo el caso de un líder que actualmente se reconoce afromexicano, al que hace diez años hice una entrevista en donde le pregunté acerca de sus ancestros. El líder respondió haciendo referencia al lugar donde nacieron sus padres, a la mezcla negra y mestiza que tenía. Después de estas referencias, me dijo que se consideraba mestizo, citando la oportunidad que tuvo de estudiar fuera de la región 
y dejar en alguna medida las costumbres del pueblo. Sin embargo, al hablar de los mestizos que tenían el poder en la región, en su discurso se distanció de los mismos, ya que apareció en su relato estereotipos que los mestizos tienen de los negros, es decir, de personas en las que se desconfía, que son violentas y flojas. El líder, al identificarse como mestizo, trató de ubicarse en la que consideró la mejor posición, la menos discriminada, dentro de los esquemas del espacio regional, tal vez atenuando con ello el marcador racial; sin embargo era notable una jerarquización mestiza. El mestizo que tiene el poder económico y político es el que encarna el modelo, y la adscripción a esta categoría no implica que se diluya la jerarquización racial y la discriminación.

De regreso al relato del líder, actualmente él forma parte de la movilización afromexicana y hoy se reivindica como negro. En el contexto de la consulta, el líder dice:

"No es que los negros no existieran antes, más bien no eran nombrados o tal vez no necesitábamos nombrarnos. Hoy, ya hay otras condiciones para reconocerse, claro, esto no quiere decir que la forma en que nos miran haya cambiado tanto, nos siguen discriminando. Las instituciones especialmente, te pongo como ejemplo, anteriormente, cuando no había reglas de operación, con todo y los prejuicios (de las instituciones) con los negros se podía lograr que apoyaran un poquito a las comunidades. Las puertas se fueron cerrando, ahora con las reglas de operación en la mano te dicen que 'no eres lo suficientemente pobre', aunque seas pobre, pero necesitas estar reconocido en las estadísticas como más marginal. O si no, te dicen 'no eres indígena'. Lo que es claro es que hay abandono institucional" (líder afrodescendiente, Costa Chica de Oaxaca, noviembre 2011).

El discurso del líder nos muestra que en otras épocas (antes de la década de 1990), no necesitaban ser nombrados porque en la política del país no estaba integrada la reivindicación de la diferencia cultural. En buena medida, la apertura de la dimensión étnica en la política nacional es una vía en donde se abre un espacio político para negociar recursos a los que no pueden acceder, y que el Estado tendría el deber de garantizar. Lo que está en debate no solo es nombrar la diferencia, por problemática que esta sea, sino además en el conjunto de derechos asociados que implica la inversión de los recursos para las comunidades.

Por el momento, el debate está centrado en la definición de la diferencia, en nombrarla de manera normativa, entendiendo que:

"El reconocimiento constitucional es la base a partir de la que se genera una esfera jurídica de protección legal de las poblaciones minoritarias, ya que apartir de este se reconocen y se protegen todos los demás derechos, generando visibilización y certeza jurídica para las poblaciones que son reconocidas, tal como sucede con las comunidades indígenas en el artículo 2 de la Constitución" (CONAPRED, 2015:249-250).

El logro del reconocimiento étnico institucional buscará "los rasgos de autenticidad para justificar la diferencia", acordes a la ideología étnica establecida y los límites que marca. El paso por la esencialización de lo afro o de lo negro parece ineludible.

Desde las voces de las personas que participaron en la consulta las formas de reconocerse son múltiples. Se alude a las identificaciones regionales, microrregionales, locales y nacionales. Las regionales se refieren a morenos y costeños; las microrregionales se refieren a espacios (ecosistemas), en particular en la costa en cómo son "los Bajos" y "la Llanada"; las locales se refieren a identificaciones comunitarias por ejemplo "Cortijanos" (de la comunidad de Cortijos); las identificaciones nacionales se refieren al ser mexicanos, incluir en el imaginario nacional la marca del color que en muchas ocasiones los hace ver como extranjeros. Sería congruente que los funcionarios de las instituciones gubernamentales, CDI e INEGI, dialogaran y tomaran las reflexiones y los cuestionamientos de la gente en la consulta y otros foros organizados por los colectivos afrodescendientes con miras a incorporar la pregunta de identificación étnica en el censo del 2020. La encuesta intercensal de 2015 arrojó varias experiencias que es necesario recoger en campo para una crítica que apoye a construir instrumentos más asertivos y asequibles para las poblaciones encuestadas. 
Es importante anotar que las respuestas de identificación son producto de una situación de encuentro entre las personas de la comunidad y personas asociadas a una institución gubernamental. Las respuestas se dan desde la posición que en ese momento toman las personas. Es decir, parafraseando a Navarrete (2015:470), la identidad no está predeterminada, se fija temporalamente, no de manera definitiva ni esencialista, se trata de un posicionamiento en un contexto determinado.

Hay preguntas que me surgen y no podré responder por ahora en este texto: $¿$ existen las condiciones de organización colectiva afrodescendiente capaces de proponer categorías de identificación desde abajo y que desafíen los límites impuestos? ¿Las expresiones de gobierno, territorialidad y concepciones de autoridad y usos y costumbres pueden pensarse desde un orden pluricultural?

\section{Conclusiones}

El esfuerzo institucional en la realización de la consulta afrodescendiente en el país sin duda tiene aportaciones significativas para empezar a conocer y visibilizar a una población olvidada en la historia nacional y por el Estado mexicano. Poner atención acerca de las creaciones culturales regionales afromexicanas dará mayor luz para entender los márgenes en los que se hallan estas poblaciones, las que se han ajustado a los límites normativos de las sociedades que comparten con indígenas y mestizos. El mestizaje no solucionó los problemas de discriminación y racismo de las poblaciones en cuestión, más bien ocultó la historicidad de las poblaciones insertas en esta categoría genérica y, a la vez, encubrió las jerarquizaciones del mestizaje.

Los cambios constitucionales al artículo $2^{\circ}$ constitucional serán un desafío, en tanto requiere un esfuerzo mayúsculo de las instituciones y los legisladores de comprender la historia y configuración de las poblaciones afrodescendientes en sus particularidades regionales. Así también, tendrán que enfrentar los límites de la ideología étnica vigente, no solo para las poblaciones afrodescendientes rurales, sino para aquellas que se reivindiquen en espacios urbanos de manera futura.

Actualmente existe un momento histórico favorable para la reivindicación afrodescendiente, la promulgación por Naciones Unidas del Decenio
Internacional de las Personas Afrodescendientes a partir de enero de 2015, incentivará al Estado mexicano a realizar acciones a favor de las poblaciones en cuestión. Además, existen diversos actores en movimiento y sinergia para el logro del reconocimiento constitucional: movimiento indígena; académicos de diferentes instituciones; organizaciones civiles de apoyo a líderazgos de mujeres y la participación institucional del Movimiento Nacional por la Diversidad Cultural en México en el que se involucran instituciones educativas y gubernamentales, entre otras. Particularmente, el movimiento indígena de Oaxaca junto con organizaciones negras y afromexicanas de la costa están en el debate y defensa de la propuesta de reforma constitucional en la entidad oaxaqueña. Dicha propuesta se entregó al gobernador en turno en el 2013. En este acto Jualiana Acevedo, representante del pueblo negro afromexicano, mencionó:

"El reconocimiento jurídico del Pueblo
Negro que contiene esta iniciativa, va
más allá de una simple enunciación o de
sentar las bases para alguna ley contra la
discriminación, el racismo y la xenofobia.
Queremos una reforma que se traduzca en
instituciones y políticas públicas que ayuden
a las comunidades, de nuestro pueblo negro
afromexicano a salir del rezago en el que
se encuentran inmersas. Para lograrlo,
este documento sustenta una nueva noción
de territorio, una forma distinta de par-
ticipación política, los derechos de libre
determinación, autonomía, así como los de
consentimiento libre previo e informado”
(SAI, 2013:207).

La movilización afromexicana busca respuestas concretas ante las condiciones de marginalidad, carencia de servicios y falta de oportunidades. Estas prioridades, que son urgentes e inmediatas dejan de lado debates que tal vez sea posible dar a la par. Siguiendo la norma jurídica los principios de igualdad y libertad están apoyados en la no discriminación y el reconocimiento de la diferencia. La discriminación y el racismo son temas por profundizar y que a la vez dan sustento a las demandas de las poblaciones en cuestión. 


\section{Referencias Citadas}

Bárcenas, Francisco

2001 "La lucha por la autonomía indígena en México: un reto al pluralismo", en Rosalba A. Hernández et al. (coords..) El Estado y los indígenas en tiempos del PAN: neoindigenismo, legalidad e identidad, México, CIESAS- Porrúa.

Bernand, Carmen

1999 Los híbridos en Hispanoamérica. Un enfoque antropológico de un proceso histórico, en Boccara y Galindo (eds.) Lógica mestiza en América, Temuco, Chile: Instituto de Estudios Indígenas-Universidad de La Frontera, pp. 61-84.

Briones, Claudia

2005 Formaciones de la alteridad: contextos globales, procesos nacionales y provinciales, en Claudia Briones (Compiladora), Cartografías argentinas: políticas indígenas y formaciones provinciales de la alteridad, Buenos Aires, Argentina: Antropofagia.

Chávez, David

2014 Lo ombre y la muhere del pehcao, Características del español hablado en la Costa Chica de Guerrero en Saúl Morales Lara, Intersecciones: la lingüística y las ciencias antropológicas en el II Coloquio Leonardo Manrique, INAH, México.

Comité para la Eliminación de la Discriminación Racial $79^{\circ}$ período de sesiones 8 de agosto a 2 de septiembre de 2011 . CERD/C/GC/34. 3 octubre de 2011.

\section{CONAPRED}

2015 Derechos colectivos y reconocimiento constitucional de las poblaciones afromexicanas, Colección Legislar sin Discriminación, Tomo VII, CONAPRED, SEGOB, Senado de la República, México.

Constitución política de los Estados Unidos Mexicanos, Diario Oficial de la Federación 9 de febrero de 2012, México.

Encuesta Intercensal

2015 Principales resultados. Instituto Nacional de Estadística y Geografía, México.

Facio Montejo, Alda

1992 Cuando el género suena cambios trae (una metodología para el análisis de género del fenómeno legal), San José, C.R.: ILANUD.

García, Ángel y Asociados, S.C.

2003 Oaxaca. Distritos, red de caminos y datos estadísticos de población y vivienda, Ed. García, Ángel y Asociados, S.C., Oaxaca, México.

García de León, Antonio

2006 Fandango. El ritual del mundo jarocho a través de los siglos. México, CONACULTA-Instituto Veracruzano de la Cultura-Programa de Desarrollo Cultural del Sotavento.

González, C.

2011 De la casta a la raza. El concepto de raza: un singular colectivo de la modernidad. México, 1750-1850, HMEX, IX: 3, 2011 pp. 1491-1524.

Hale, Charles

2007 Mistados, cholos y la negación de la identidad en la Sierra de Guatemala, en Marisol Cadena, Formaciones de la indianidad. Articulaciones raciales, mestizaje y nación en América Latina, Envion, Colombia.

Hernández, Rosalba A.

2001 "La diferencia en debate: la política de identidades en tiempos del PAN", en Rosalba A. Hernández et al. (coords..) El Estado y los indígenas en tiempos del PAN: neoindigenismo, legalidad e identidad, México, CIESAS-Porrúa.
Hoffmann, Odile y Gloria Lara

2012 "Reivindicación afromexicana: formas de organización de la movilización negra en México", en Becerra, María José; Buffa, Diego; Noufouri, Hamurabi y Ayala, Mario (comps.), Las poblaciones afrodescendientes de América Latina y el Caribe. Pasado, presente y perspectivas desde el siglo XXI, Argentina: Universidad Nacional Tres de Febrero-Centro de Estudios Avanzados de la Universidad Nacional de Córdoba y Cátedra UNESCO.

Hoffmann, Odile

2007a Población de origen africano y afrodescendientes: las Américas negras contemporáneas. Boletín INAH, 07, marzo-abril, México, Instituto Nacional de Antropología e Historia, pp. 4-9.

Hoffmann, Odile

2007b De las 'tres razas' al mestizaje: diversidad de las representaciones colectivas acerca de lo ‘negro' en México. (Veracruz y Costa Chica). Diario de Campo. Suplemento 2007, Núm. 42, marzo-abril, México, Instituto Nacional de Antropología e Historia, 98-107 pp.

Hoffmann, Odile

2010 "Afroveracruzanos", en Enrique Florescano y Juan Ortiz Escamilla (coords.), Atlas del patrimonio natural, histórico y cultural de Veracruz, vol. 2 , Gobierno del Estado de Veracruz, Universidad de Veracruz.

Hooker, Juliet

2012 "Las luchas por los derechos colectivos de los afrodescendientes", en Política e identidad. Afrodescendientes en México y América Central. CNCA-INAH, CEMCA, UNAM-CIALC, IRD, México.

Informe de la Conferencia Mundial contra el Racismo, la Discriminación Racial, la Xenofobia y las Formas Conexas de Intolerancia. Durban, 31 de agosto a 8 de septiembre de 2001. Organización de las Naciones Unidas.

Informe final de la Consulta para la identificación de comunidades afrodescendientes. México: Comisión Nacional para el Desarrollo de los Pueblos Indígenas, 2012.

Katzew, Ilona

2004 La pintura de castas: representaciones raciales en el México del siglo XVIII. Madrid: Turner: Consejo Nacional para la Cultura y las Artes, 239 p. [Título original: Casta painting: images of race in eighteenth-century México.]Figura 91. Atribuido a José Ibarra, De negro e india, lobo, c. 1725, óleo sobre lienzo, 164 x 91 cm. Colección particular, España.

Knight, A.

1990 "Racism, revolution, and indigenismo: Mexico, 19101940". En R. Graham (Comp.), The idea of race in Latin America, 1870-1940. Austin: Universityof Texas Press.

Lara, Gloria

2010 "Referentes étnico-políticos para decir 'lo negro' en la Costa Chica de Oaxaca", en Odile Hoffmann (Coord.), Política e identidad. Afrodescendientes en México y América Central, México: CEMCA/INAH/CIALC-UNAM/IRD.

Lara, Gloria

2012 Espacios, sociedades y acción institucional en la Costa de Oaxaca. México, CONACULTA-Secretaría de las Culturas y las Artes de Oaxaca.

Lara, Luis Fernando

2015 "Africanismos en el español de México", en Nueva Revista de Filología Hispánica, vol. LXIII, núm. 2, 2015, COLMEX, pp. 297-336. 
Lipski, John M.

2007 "El lenguaje afromexicano en el contexto de la lingüística afrohispánica". Publications of the Afro Latin American Research Association (PALARA), v. 11, pp. 33-45.

Moreno, Mónica

2008 "Negociando la pertenencia: Familia y mestizaje en México", en Wade, Peter, Urrea Giraldo, Fernando Viveros Vigoya, Mara, (eds.) Raza, Etnicidad y Sexualidades: Ciudadanía y Multiculturalismo en América Latina. Bogota: Centro de Estudios Sociales, Universidad Nacional de Colombia.

Nava, Fernando

2016 Un canto religioso de los negros mascogos. Anales de Antropología 50(2016), IIA, UNAM p. 336-341.

Naveda, Adriana

1990 Algunas consideraciones sobre Veracruz en el Caribe, esclavitud y cimarronaje, en Anuario VII, Centro de Investigaciones Históricas. Instituto de Investigaciones Humanísticas. Universidad Veracruzana, pp. 7-15.

Olveda, J.

2013 La abolición de la esclavitud en México 1810-1927, Signos Históricos, núm. 29, enero-junio, 2013, pp. 8-34.

Paz, Sarela

2001 "Pensando la diferencia en su posibilidad política", en Rosalba A. Hernández et al. (coords.), El Estado y los indígenas en tiempos del PAN: neoindigenismo, legalidad e identidad, México, CIESAS-Porrúa.

Pérez, Ricardo

2007 "El negro y la negritud en la formación del estereotipo jarocho durante los siglos XIX y XX, en expresiones populares y estereotipos culturales en México siglo XIX y XX: diez ensayos", México, CIESAS.

Poole, Deborah

2005 "Diferencias ambiguas: memorias visuales y el lenguaje de la diversidad en la Oaxaca posrevolucionaria", en Revista Mexicana de Ciencias Políticas y Sociales, vol. XLVII, núm. 195, septiembre-diciembre, UNAM, pp. 125-162.

Programa de revitalización, fortalecimiento y desarrollo de las lenguas indígenas nacionales

2008-2012 Instituto Nacional de las Lenguas Indígenas. 6 de octubre de 2008.

Rinaudo, Christian

2012 Afromestizaje y fronteras étnicas. Una mirada desde el puerto de Veracruz, México, Universidad Veracruzana-IRD.

Urías Horcasitas, Beatriz

2007 Historias secretas del racismo en México (1920-1950), México, Tusquets.

Velázquez, María Elisa y Gabriela Iturralde

2016 "Afromexicanos: reflexiones sobre las dinámicas del reconocimiento", en Anales de Antropología 50, UNAM, México, pp. 232-246.

Vinson III Ben y Bobby Vaughn

2004 Afromexico. México, Fondo de Cultura Económica.

Wade, Peter

2003 Repensando el mestizaje. Revista Colombiana de Antropología vol. 39, Bogotá Jan/Dec.

Zerecero, Anastasio

2010 Memorias para la historia de las revoluciones en México, México, Instituto de Investigaciones HistóricasUNAM, México.

\section{Notas}

1 Véase Artículo 16 de Constitución Política del Estado Libre y Soberano de Oaxaca, decreto publicado en el periódico oficial el 30 junio de 2015 y Artículo 8 de la Constitución Política del Estado Libre y Soberano de Guerrero, decreto publicado el 29 de abril de 2014. En el texto emplearé el término afrodescendiente para hacer referencia a instrumentos jurídicos internacionales y el término afromexicanos o negros para referirme a las poblaciones que habitan en la Costa Chica de Oaxaca y Guerrero en México. La categoría local utilizada institucionalmente es de poco uso en las comunidades, los términos moreno y negro son los más comunes en el diálogo cotidiano.

2 La última etapa de la trata esclavista refiere a fines del siglo XVIII (véase, Naveda, 1990).

3 Para mayor profundidad acerca de los cuadros de castas véase Katzew, I. (2004). La pintura de castas y representaciones raciales en el México del siglo XVIII. Madrid: Turner: Consejo Nacional para la Cultura y las Artes.

4 González (2011:1510) afirma que la hibridez contenida en el concepto de casta seguirá vigente a comienzos del siglo XIX y que la idea de "blanco" y "casta" devienen de metáforas de la raza, entendiendo que en el escenario político independiente el horizonte cultural es lo ilustrado, occidental y moderno.

5 La cuestión de la abolición de la esclavitud proclamada en 1810 tiene dos referentes explícitos: el primer decreto el 19 de ocubre de 1810 bajo la orden de Miguel Hidalgo y Costilla; el segundo, el bando expedido por José María Morelos y Pavón el 17 de noviebre de 1810. Posteriormente, el bando del 6 de diciembre de 1810 no suprime, prohíbe o se menciona la abolición de la esclavitud, sino ordena dar libertad a los esclavos (Olveda, 2013:14). Al respecto, Zerecero (2014:134) menciona que las razones de la abolición de la esclavitud proclamada por Miguel Hidalgo tuvieron la intención de afectar la propiedad de los españoles, impedir que los esclavos fueran utilizados como esclavos e impulsar la participación de los mismos en la rebelión por la independencia. El estudio de Olveda (2013) nos muestra que las disposiciones proclamadas han sido sobreestimadas, en tanto que el control de las ordenanzas difícilmente podía llevarse a cabo en un territorio tan amplio y en estado de guerra independiente. La existencia de bandos posteriores insistiendo en la abolición de la esclavitud, la existencia de práctica: artículo 24 de los Elementos Constitucionales de 1812, Los Sentimientos de la Nación en 1813.

6 Urías (2007) menciona que los programas gubernamentales apuntaron a: a) modificar la mentalidad y conciencias de los ciudadanos mediante la educación laica, fortalecimiento de valores patrióticos y familiares; b) la necesidad de unidad racial, basada en el mestizaje y en la erradicación de lo que se consideraba herencia degenerada. Entonces, la identificación de caracteres degenerados apuntaba a determinados individuos y grupos étnicos; c) las políticas demográficas promovieron la inmigración de individuos preferentemente 
de raza blanca; d) la intervención de médicos y psiquiatras para controlar la reproducción de anormales, entendidos como los que padecían alcoholismo, toxicomanía, epilepsia, enfermedades mentales y venéreas y desviación sexual.

7 Véase Hoffmann, Odile, 2006. "Negros y afromestizos: viejas y nuevas lecturas de un mundo olvidado", $68, \mathrm{~N}^{\circ} 1$ (enero-marzo), Revista Mexicana de Sociología, UNAM; Velázquez, María Elisa y Ethel Correa, 2008. Antología de textos Afromexicanos y afrodescendientes en México, Cuaderno de trabajo $\mathrm{N}^{\circ} 3$, Proyecto AFRODESC.

8 De acuerdo con Briones (2005 en Briones, 2002), la racialización se entiende como "una forma social de marcación de alteridad que niega la posibilidad de que cierta diferencia/ marca se diluya completamente, ya por miscegenación, ya por homogeneización cultural, descartando la opción de ósmosis por medio de las fronteras sociales, esto es, de fusión en una comunidad política envolvente que también se racializa por contraste". Se define etnicización como "aquellas formas de marcación que, basándose en 'divisiones en la cultura' en vez de 'en la naturaleza', contemplan la desmarcación/ invisibilización y -apostando a la modificabilidad de ciertas diferencias/marcas- prevén o promueven la posibilidad general de pase u ósmosis entre categorizaciones sociales con distinto grado de inclusividad".

9 La categoría de mestizo obliga a la reflexión histórica de su significado, transformación en el tiempo y las jerarquizaciones contenidas. Bernard (1999) nos da múltiples pistas para el período colonial y siglo XIX. En el período colonial, las castas del color reúnen a todos los frutos del mestizaje, cuyas referencias de origen han desaparecido, y en tanto desprovistas de raíces étnicas son evidenciadas por el tamiz del color. La hibridez, afirma la autora, es ambivalencia y desconfianza, y jurídicamente se termina en el siglo XIX dando paso a la categoría de ciudadanos. Posteriormente, el mestizaje adquiere significados positivos en el siglo XX como la raza de bronce (Vasconcelos, 1948), sin embargo, esto no significa que el tamiz del color desapareciera de las marcaciones o jerarquizaciones sociales.

10 En concordancia con la postura de Hoffmann, O. (2010:133), más que establecer un mapa de "territorios definidos", se trata de una representación de lugares asociados a lo negro.

11 A la lengua también se le denomina criollo (o creole) afroseminol, seminol negro, o seminol (véase Nava, Fernando (2016:337).

12 Odile Hoffmann (2007b) afirma que la presencia negra forja junto con la indígena y española la identidad "jarocha", la que no forma parte del conjunto de grupos étnicos, sino que aparece como una identificación regional (Sur de Veracruz) y se asume como mestiza. Para mayor profundidad en el tema consulte: Rianudo (2011); Hoffmann, O. (2010); Pérez, R. (2007) y García de Léon, A. (2006).

13 En este año hubo reformas constitucionales para incluir los derechos de los pueblos indígenas en la Constitución Federal. Especialmente el artículo $2^{\circ}$ describe como comunidades indígenas "aquellas que formen una unidad social, económica y cultural, asentada en un territorio y que reconocen autoridades propias de sus usos y costumbres". Adicionalmente se menciona en este artículo que "toda comunidad equiparable a aquellos tendrá en lo conducente los mismos derechos, tal y como establezca la ley".
14 Revise Hoffmann y Lara (2014), cuya investigación profundiza en el tema.

15 El autor citado hace un amplio trabajo de investigación para el caso de la ciudad de Veracruz, para mayor profundidad consulte su obra afromestizaje y fronteras étnicas, Universidad Veracruzana.

16 A nivel nacional se estima que la población afrodescendiente asciende a 1.381 .853 personas. El cálculo se basa en el criterio de autoadscripción. La pregunta realizada fue "De acuerdo con su cultura, historia y tradiciones ¿(nombre) se considera negra (o), es decir, afromexicana o afrodescendiente? El país está compuesto por 32 estados: en 3 de ellos se concentra la mayor parte de la población afrodescendiente (14,7\%); en 15 estados se reúne el 9,4\% y solo en 7 de ellos las cifras son del $0,0 \%$ (véase EIC, 2015).

17 El rezago social según CONEVAL no se trata de una medida de la pobreza, sin embargo este índice mide cuatro carencias sociales asociadas a la medición de pobreza: rezago educativo, acceso a los servicios de salud, acceso a los servicios básicos en la vivienda y la calidad y espacios en la vivienda (CONEVAL, 2015).

18 Me refiero al Pacto Internacional de Derechos Económicos, Sociales y culturales; Pacto Internacional de Derechos Civiles y Políticos; Declaración Universal de Derechos Humanos; el artículo 14 de la Convención Europea de los Derechos Humanos y el artículo 2 de la Convención sobre los Derechos del Niño (citado en CONAPRED, 2015:15-17).

19 Para la consulta del documento completo véase $\mathrm{CERD/C/}$ GC/34. 3 octubre de 2011. Comité para la Eliminación de la Discriminación Racial $79^{\circ}$ período de sesiones 8 de agosto a 2 de septiembre de 2011. Disponible en http:// www.acnur.org/t3/fileadmin/Documentos/BDL/2012/8466. pdf?view $=1$

20 El CONAPRED es un organismo descentralizado, dependiente de la secretaría de la Gobernación. El Consejo se establece como " la institución rectora para promover políticas y medidas tendientes a contribuir al desarrollo cultural y social y avanzar en la inclusión social y garantizar el derecho a la igualdad, que es el primero de los derechos fundamentales en la Constitución Federal". Disponible en www.conapred.org.mx . Consulta realizada 1 de agosto de 2016.

21 Véase nota: México, D.F., 18 junio 2015.- El día de hoy se celebró en la Secretaría de Relaciones Exteriores (SRE) la primera Reunión de Alto Nivel de 2015. Disponible en http://www.conapred.org.mx/index. php? contenido $=$ registro_encontrado $\&$ tipo $=2 \&$ id $=5536$

22 La CDI es creada en el 2003, actualmenye es un organismo descentralizado, no sectorizado de la Administración Pública Federal, con personalidad jurídica y patrimonio propio, que goza de autonomía operativa, técnica, presupuestal y administrativa (véase Diario Oficial de la Federación, 19 de enero de 2016). En ley de creación de este organismo se establece que la Comisión contará con un Consejo Consultivo como órgano de consulta y vinculación con los pueblos indígenas y la sociedad. Dicho Consejo es un órgano colegiado integrado por 198 representantes; 140 de ellos son integrantes de los pueblos indígenas, 7 de instituciones académicas, 12 de organizaciones sociales, 7 del Congreso de la Unión y 32 de representantes de cada 
gobierno estatal. Por mandato de Ley el Consejo Consultivo está integrado mayoritariamente por indígenas. Disponible en http://www.cdi.gob.mx/consultivo/index.html

23 Las organizaciones que participaron fueron: México Negro A.C.; Enlace de Pueblos y Organizaciones y Comunidades Autónomas, A.C. (EPOCA); Alianza para el Fortalecimiento de las Regiones Indígenas y Comunidades Afromexicanas, A.C. (AFRICA) y Ecosta Yutucuii S.S.S.(ECOSTA).

24 Además de los elementos descritos se consideró agregar la dimensión de disriminación y racismo.

25 Para mayor profundidad véase la propuesta de CONAPRED (2014:413-425)

26 "Los rasgos lingüísticos pertenecen al macrodialecto 'costeño' que incluye no solo la costa del Caribe sino también la costa del Pacífico, desde Baja California Sur pasando por Acapulco hasta llegar a la Costa Chica de Oaxaca (Lipsky, 2007: 38). La raíz histórica según Lipsky refiere al habla de Andalucía, lugar donde se reducen las consonantes finales aun en los sociolectos más cultos.

27 Lara (2015:314:315) afirma que en la Nueva España no existen documentos que indiquen la existencia de un pidgin o un protocriollo, como sí es el caso que muestra Lipsky para Cuba. El autor menciona: "en su vertiente del Golfo, en la cadena caribeña que corresponde al actual México y en la costa de Guerrero solo se conserva la aspiración de /s/ implosiva y final de palabra[...] no se pudieron formar lenguas criollas por las siguientes causas: a) si acaso llegó un pidgin afroamericano, desapareció al paso de los siglos, pues no hubo condiciones para que los negros se vieran empujados a formar palenques, que los dejaran completamente aislados de la sociedad novohispana; b) la aspiración de /s/ implosiva y en final de palabra es de origen andaluz, como sostuve antes, y propia de una población andaluza en toda Hispanoamérica que, aunque minoritaria frente a los indios y los negros, era socialmente dominante y fue la que determinó la asimilación de los africanos al español en la costa del Golfo de México; c) el hecho de que los africanos se mezclaran rápidamente con indias, para las que el español se convertía en la lengua de comunicación, ante la dificultad de que los negros aprendieran la lengua amerindia o que ellas aprendieran alguna de las lenguas africanas, socialmente inútiles, lo que impedía la conservación de sus propias lenguas y del supuesto "protocriollo", y d) el predominio del español de los indios y los mestizos, que muy pronto debe haber llegado a diseminarse por la Nueva España como el dialecto predominante".

28 Los discursos en México cambiaron en la década de 1990, de la promoción abierta del mestizaje a una reivindicación de las culturas indígenas como "patrimonio nacional" (Hernández, 2001). En el transcurrir de esta década ya no solo se hablaba de demandas campesinas, en el discurso el indio ya era permitido.

29 Briones (2005:11) menciona que transnacionalización se entiende como "una re territorialización de prácticas económicas, políticas y culturales que, reconfigurando el "orden internacional", resultan en el aumento y la diversificación de los flujos de población, productos, información, etc., las luchas indígenas han quedado enmarcadas en y por una serie de peculiaridades".

30 Aquí no discutiré las teorizaciones académicas alrededor de la etnicidad, que han abonado conceptualizaciones científicas a la par de estos procesos, que no es el objeto de la discusión del texto.

31 Poole (2005:217-218) nos detalla que la fiesta de la Guelaguetza se inició en 1932 en Oaxaca como un "homenaje racial", hoy se autodenomina como un legado ritual zapoteca. En este festival, a partir del año 2000 participan danzantes afromexicanos. Algunos miembros del Comité de organización de la Guelaguetza no estuvieron de acuerdo con la participación de los afromexicanos en la festividad, ya que la danza desde su punto de vista está fuera de contexto indígena, se percibe que no hay conexiones posibles y solo se aceptó su presencia por compromiso político. Acorde con la crítica anterior, una periodista llegó a comentar en su nota que "la negra es raza no una etnia".

32 Hale (2007:235) define el término de ideología étnica "a un conjunto de categorías sociales constituidas históricamente, que la gente emplea para ubicarse a sí misma, para describir a otros, y para trazar fronteras entre 'nosotros' y 'ellos"'. Dicho concepto "son representaciones predominantes de los procesos sociales complejos, que ineludiblemente homogeneizan y simplifican experiencias y formas de pensar particulares, e inevitablemente promueven ciertos intereses y subordinan otros". 